\title{
BLACK-FOOTED FERRET (MUSTELA NIGRIPES) REstoration IN BADlands National PARK 1994-1995
}

\begin{abstract}
$\longrightarrow$
\section{SITE SELECTION AND PREPARATION}

During spring 1994, three black-tailed prairie dog colonies totaling 403 ha within Badlands National Park were selected as locales to release ferrets during fall. This area was selected based on quality of habitat, remoteness from visitors and accessibility for field crews and is located within the Badlands Wilderness Area where mechanical transport is prohibited and approximately 550 bison range freely. Forty proposed release cages were stratified across the 3 colonies based on topography and degree of prairie dog activity. A helicopter was used to airlift over $8,000 \mathrm{lbs}$ of supplies used for construction of 28 release cages/bison exclosures in the Badlands Wilderness Area several months prior to black-footed ferret arrival.
\end{abstract}

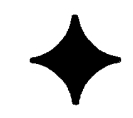

\author{
GLENN E. PLUMB $\downarrow$ WILDLIFE BIOLOGIST \\ BADLANDS NATIIONAL PARK $\downarrow$ INTERIOR, SD
}

\section{BLACK-FOOTED FERRET ALLOCATION}

From September 1994 to October 1995, 69 juvenile and 32 adult black-footed ferrets have been allocated and released in Badlands National Park. Project biologists have worked with the National Biological Survey (NBS) and facility veterinarians at Toronto Metro Zoo, Henry Doorly Zoo and Wyoming Game and Fish Department's Sybille Wildlife Research and Conservation Center to fit radio telemetry collars on 63 ferrets ( 45 juveniles and 18 adults) Upon arrival at Badlands NP, ferrets were transported to the Badlands Wilderness Area boundary and backpacked directly to their preselected release sites. Local media often provided coverage of ferret arrivals.

\section{BLACK-FOOTED FERRET HUSBANDRY}

Naive animals (no previous exposure to prairie dogs or burrow systems while in captivity) were held in release cages for a minimum of 10 days with a minimum 5 day post-release cage attending period (soft release). Pre-conditioned animals (having the opportunity to live in captive outdoor prairie dog enclosures and hunt prairie dogs) were held in a release cage for a maximum of 48 hours with no post-release cage attending (hard release). Release cage environments included a fitch box, food tube, water bowl, and a connected nest box located in an underground vault.

Project staff were trained by Wyoming Game and Fish staff at Sybille in handling, cage attending and examining ferrets. Only trained staff were used for release cage attending. Cage attendants were also trained in detection of coccidiosis by the project veterinarian and periodic testing of stools occurred. During releases, cage attendants fixed a variable length of $4^{\prime \prime}$ plastic tubing between the release cage exit door and nearest active prairie dog burrow. Cages were opened at sunset and attendants immediately left the site.

\section{BLACK-FOOTED FERRET MONITORING}

Post-release monitoring by radio telemetry, spotlighting and snowtracking has been conducted following reintroductions in fall 1994, spring 1995, and fall 1995. Badlands National Park received 
precedent setting permission to operate nighttime aerial telemetry missions from the Federal Office of Aircraft Services. Telemetry equipment was loaned to Badlands National Park from National Biological Service in Colorado and California. During fall 1994, six nighttime aerial telemetry flights were conducted in parallel with ground telemetry conducted for 21 days post-release. A total of sixtytwo individual locations were detected with $97 \%$ occurring within the 3 release colonies. A majority of telemetry locations (70\%) were collected during the first week post-release. Animals moved freely among the 3 release colonies but dispersal within 3 weeks post-release is believed to be limited primarily to less than five miles. Spotlight surveys conducted from November 28 to December 10, 1994 detected eight individual animals. Post-release surveys following a spring 1995 release of 26 preconditioned four and five year old adult blackfooted ferrets indicated no survivorship within two weeks after release to the wild. Telemetry, spotlight, and snowtrack surveys following the fall 1995 reintroduction detected sixteen black-footed ferrets including 9 juveniles released in October 1995, two adults (released as juveniles in 1994), three wildborn kits, and two as yet unidentified animals. These measures of minimum juvenile survivorship (28-30\%) exceed the 30 day postrelease goal articulated in the 1994 and 1995 Reintroduction Protocols.

\section{FUTURE OPERATIONS}

It is expected that reintroductions of blackfooted ferrets will continue in and adjacent to Badlands National Park during 1996 - 1998 in order to establish the first self-sustaining, viable wild population since the Meteetsee, Wyoming population was captured from the wild in 1985. Continuing development of new sampling procedures to evaluate post-release survivorship and black-footed ferret and associated predator guild population status will be a high priority for continuing research efforts at Badlands National Park during this time.

\section{ACKNOWLEDGEMENTS}

Due to a Fiscal Year 1994 shortfall in parkbased FTEs available for this NPS Natural Resource Preservation Project, a work order under a Cooperative Agreement between the University of Wyoming and Rocky Mountain Region was initiated to transfer funds to the University of WyomingNational Park Service Research Center for the purposes of supporting three seasonal biotechnician positions to directly support the 1994 black-footed ferret reintroduction at Badlands National Park. 